\title{
Otitis Media with Effusion in Children Aged 2-12 Years Attending the Paediatric Clinic at Mulago National Referral Hospital, a Ugandan Tertiary Hospital: A Cross-Sectional Study.
}

Kabagambe Bamaraki ( $\sim$ kbgmbe2010@yahoo.fr)

Makerere University

Justine Namwagala

Makerere University

Rym Hidour

Makerere University

Emma Nsalazi Bambi

Makerere University

\section{Research Article}

Keywords: Otitis media with effusion, Hearing loss, Children, Prevalence, Associated factors

Posted Date: January 20th, 2022

DOI: https://doi.org/10.21203/rs.3.rs-1135784/v1

License: (c) (1) This work is licensed under a Creative Commons Attribution 4.0 International License.

Read Full License 


\section{Abstract \\ Background}

Otitis media with effusion (OME) is common in children aged between 6 months to 4 years, and it is one of the causes of hearing loss $(\mathrm{HL})$ in children worldwide. OME is a type of inflammation of the middle ear in which there is collection of the fluid. The later causes $\mathrm{HL}$ which interferes with speech and language development, communication skills, school performance, psychosocial skills, and quality of life of children.

\section{Methods}

This was a prospective cross-sectional study on 246 children aged $2-12$ years, attending Mulago National Referral Hospital (MNRH). Consecutive sampling procedure was used to reach each participant under ethical considerations until the sample size was reached. All children aged 2-12 years who meeting inclusion criteria were examined first by the Paediatrician and then by the Principal Investigator. Patients who had diagnosis of OME following the otoscopy and tympanometry findings were then proceed for audiological assessment. Prevalence of OME was summarized as a proportion and multivariate analysis was used to determine the factors associated with OME. Data was analyzed using STATA version 13.0.

\section{Results}

A total of 246 children were recruited into the study. Of the 246 children, $60 \%$ were male. The median age of the participants was $4.8 \pm 2.8$ years. The prevalence of OME was found to be $11 \%$. Upper respiratory tract infections (URTI), recurrent AOM ( $p=0.005$, OR:5.14, 95\% Cl: 1.66-15.96), and snoring ( $p=0.000$, OR: $6.32,95 \% \mathrm{Cl}: 2.32-17.26)$ were found to be strongly associated with OME in children aged 2-12 years attending $\mathrm{MNRH}$.

\section{Conclusions}

The prevalence of OME among children 2-12 years attending MNRH was found to be $11 \%$. There is association between OME and URTI, recurrent AOM, and snoring in children aged 2-12 years attending $\mathrm{MNRH}$.

\section{Background}

Otitis media with effusion (OME) is common in children aged between 6 months to 4 years, and it is one of the causes of hearing loss $(\mathrm{HL})$ in children worldwide. Otitis media with effusion is one of the most commonly occurring childhood illnesses in the United States of America (USA), with more than 2.2 million diagnosed cases each year [1]. 
The prevalence of OME reported from the developed countries, USA 15 to $30 \%$ in adolescents [2], $63.9 \%$ in Italy in children with lower respiratory tract infection [2].

In developing countries, India with 32.3\% [3], and Africa countries, South Africa has a prevalence of $16.5 \%$ in children attending a primary healthcare clinic [4], Nigeria 25.2\% in school age children [5], and Uganda $14.1 \%$ in school going children [6]. Otitis media with effusion is a type of inflammation of the middle ear in which there is collection of fluid. It is mostly due to a blockage or dysfunction of the Eustachian tube $(E T)$, most often between the ages of 6 months and 4 years. This later causes HL which interferes with speech and language development, communication skills, school performance, psychosocial skills, and quality of life of children [7-9].

\section{Methods}

\section{Study design,setting and population}

This was a prospective cross-sectional study carried out among children aged 2 to 12 years, attending the Paediatric clinic at Mulago National Referral Hospital, Kampala, Uganda from February 2019 to April 2019. The inclusion criteria were all children aged 2-12 years, attending the Paediatric clinic at MNRH, all children whose parents or guardians consented and assented children with age more than 8 years. The exclusion criteria were children with chronic ear infections, perforation of the tympanic membrane; children who were sick and needed to be admitted, and uncooperated children.

\section{Study procedure}

Recruitment of participants was done at the Paediatric Clinic, Mulago National Referral Hospital. Consecutive sampling was used on those who satisfy the eligibility criteria until the sample size was achieved. The research assistants and/or the principal investigator comprehensively explained to the parents or caretakers of the selected participants the purpose of the study, benefits, risks and thereafter requested for their participation. The eligible patients who agreed to participate signed a consent/assent form by writing their name and signature and subsequently were assigned a study number. Participants were then interviewed after seeing the Paediatrician or Clinician. They were examined and underwent otoscopy and tympanometry by the PI assisted by an Audiologist and the Paediatrician in the consultation room of Paediatric Clinic. The diagnosis of OME was confirmed following the otoscopy findings (dull, bulging ear drum, presence of air bubble or air-fluid level) and tympanometry findings (tympanogram type B).

\section{Otological exam}

Otoscopy was performed by the PI using Welch-Allyn otoscope. This included the status of the tympanic membrane, normal, dull, bulging, presence of air bubble or air-fluid level, absence or presence of perforation with or without pus discharge, ... The children who didn't have wax, tympanic membrane perforation, ear discharge, were sent for the next test which was the tympanometry. Participants with 
impacted wax were advised to use a cerumen softener for three days. After use of the softener, ear syringing was carried out then followed by audiological assessment.

\section{Statistical data analysis}

Analysis of the data collected was done using a computer statistical software EPI-DATA version 3.1 with automatic checks to avoid double entry of a questionnaire. The entered data was then exported to STATA version 13.0 for data cleaning and analysis with the help of a professional statistician. Continuous variables were analyzed using mean, standard deviations, median and interquartile ranges while categorical variables were presented using tables, bar graph, and pie-charts.

The prevalence of OME in children aged 2-12 years was determined using simple proportions, i.e., by calculating the number of children with OME 2-12 years divided by the total number of children recruited into the study. The associated factors were assessed in steps: bivariate analysis followed by multivariate analysis, with variables with a $p$-value $<0.2$ at bivariate analysis being included in the multivariate model, using logistic regression. The results were presented using odds ratios and $P$ values whereby, the $P$ value of 0.05 was used as the measure of statistical significance when considering $95 \%$ confidence intervals.

\section{Ethical approval.}

Permission letter to carry out the study was obtained from ENT Department, College of Health Sciences (CHS), Makerere University, School of Medicine Research and Ethics Committee (SOMREC). A written informed consent/assent was sought from parents/caretakers/children before recruitment into the study, and it included a clear explanation of the purpose of the study, the possible benefits and risks.

\section{Results}

Between February 2019 to April 2019, a total of 256 children attending Paediatric Clinic in Mulago Hospital were invited to participate in the study; 4 caretakers decline to consent, 2 were outside the required age range of 2-12years, 4 were unable to participate due to other reasons and 246 were recruited.

\section{Demographic profile and clinical characteristics of the study participants.}

Table 1 below shows the socio-demographic characteristics of the study participants (Table 1).

Among the 246 children recruited aged 2-12 years, the mean age of the participants was $4.8 \pm 2.8$. Most of the participants $154 / 246$ (63\%) were aged 2-4 years while 22/246 (9\%) within the age group of 8-10 years and $17 / 246(7 \%)$ were within the age group of $11-12$ years (Figure 1). Overall, $147 / 246(60 \%)$ of the children were male. The histogram below shows the age distribution of the study participants (Figure 1).

\section{Table 1: Shows socio-demographic characteristics of study participants}




\begin{tabular}{|c|c|c|c|}
\hline Characteristic & & Frequency $(n=246)$ & Percentage (\%) \\
\hline \multirow[t]{4}{*}{ Age in years (Mean $\pm S D$ ) } & $2-4$ & 154 & 63 \\
\hline & $5-7$ & 53 & 21 \\
\hline & $8-10$ & 22 & 9 \\
\hline & $11-12$ & 17 & 7 \\
\hline \multirow[t]{2}{*}{ Sex of the child } & Male & 147 & 60 \\
\hline & Female & 99 & 40 \\
\hline \multirow[t]{2}{*}{ School attendance } & Yes & 173 & 70 \\
\hline & No & 73 & 30 \\
\hline \multirow[t]{4}{*}{ Breastfeeding duration } & Never & 1 & 1 \\
\hline & $<6$ months & 5 & 2 \\
\hline & 6-12 months & 26 & 10 \\
\hline & $>12$ months & 214 & 87 \\
\hline \multirow[t]{2}{*}{ Breastfeeding position } & Head raised & 238 & 97 \\
\hline & Flat & 8 & 3 \\
\hline \multirow[t]{2}{*}{ Mothers' education } & No/low education & 90 & 37 \\
\hline & High/Tertiary & 156 & 63 \\
\hline \multirow{3}{*}{ Family size } & $\leq 3$ people & 38 & 15 \\
\hline & $4-6$ & 164 & 67 \\
\hline & $\geq 7$ & 44 & 18 \\
\hline
\end{tabular}

\section{Prevalence of OME in children aged 2-12 years attending the Paediatric Clinic at MNRH}

Among the 246 children recruited aged 2-12 years, the prevalence of OME in this study was $11 \%(26 / 246)$ as shown in figure 2 below (Figure 2). Children without OME were 220/246(89\%). All 26 patients with OME presented bilateral OME.

\section{Factors associated with OME among children 2-12 years attending Paediatric clinic}

Using the bivariate analysis, the table below shows history of frequent AOM ( $p<0.001$, OR:6.75, 95\% $\mathrm{Cl}: 2.60-17.54)$; allergy ( $p=0.007$, OR:3.24, 95\% Cl:1.38-7.61), snoring ( $p<0.001$, OR:7.66, 95\% Cl:3.2317.18), delayed speech ( $p=0.005, \mathrm{OR}: 3.67,95 \% \mathrm{Cl}: 1.48-8.93$ ) were significantly associated with OME. Important to know also is that, all 26 children who had tympanogram type B for both ears, had history of 
frequent URTI. Other factors like age, sex, school attendance, mothers' education, family size, and exposure to smoking were not directly associated with OME as shown in a table below (Table 2):

Table 2: Shows bivariate analysis of socio demographic characteristics with OME in children aged 2-12 years attending the Paediatric clinic at MNRH. 


\begin{tabular}{|c|c|c|c|c|c|}
\hline \multirow[t]{3}{*}{ Characteristics } & \multirow{3}{*}{$(M e a n \pm S D)$} & \multirow{3}{*}{$\begin{array}{l}\text { Had Type "B" } \\
(n=26) \\
3.3 \pm 1.6\end{array}$} & \multirow{2}{*}{$\begin{array}{l}\text { No type } \\
\text { B } \\
(n=220)\end{array}$} & \multirow{3}{*}{ OR (95\% Cl) } & \multirow{3}{*}{$\begin{array}{l}\text { P- } \\
\text { value* }\end{array}$} \\
\hline & & & & & \\
\hline & & & $4.9 \pm 2.9$ & & \\
\hline \multirow[t]{4}{*}{ Age in years } & $2-4$ & $24(92)$ & $130(59)$ & $\begin{array}{l}0.26(0.03- \\
2.01)\end{array}$ & 0.196 \\
\hline & $5-7$ & $1(4)$ & $52(24)$ & $\begin{array}{l}2.48(0.15- \\
41.45)\end{array}$ & 0.528 \\
\hline & $8-10$ & $1(4)$ & $21(10)$ & - & - \\
\hline & $11-12$ & $0(0)$ & $17(9)$ & Ref & \\
\hline \multirow[t]{2}{*}{ Sex } & Male & $17(65)$ & $130(59)$ & $\begin{array}{l}1.31(0.56- \\
3.06)\end{array}$ & 0.537 \\
\hline & Female & $9(35)$ & $90(41)$ & Ref & \\
\hline \multirow[t]{2}{*}{$\begin{array}{l}\text { School } \\
\text { attendance }\end{array}$} & Yes & $21(81)$ & 152 (69) & $\begin{array}{l}1.88(0.68- \\
5.19)\end{array}$ & 0.224 \\
\hline & No & $5(19)$ & $68(31)$ & Ref & \\
\hline \multirow[t]{2}{*}{$\begin{array}{l}\text { Mothers' } \\
\text { education }\end{array}$} & $\begin{array}{l}\text { No/low } \\
\text { education }\end{array}$ & $11(42)$ & $79(36)$ & $\begin{array}{l}1.31(0.57- \\
2.99)\end{array}$ & 0.523 \\
\hline & High/Tertiary & $15(58)$ & $141(64)$ & Ref & \\
\hline \multirow{3}{*}{ Family size } & $\leq 3$ people & $2(8)$ & $36(16)$ & Ref & \\
\hline & $4-6$ & $20(77)$ & $144(66)$ & $\begin{array}{l}0.40(0.09- \\
1.79)\end{array}$ & 0.231 \\
\hline & $\geq 7$ & $4(15)$ & $40(18)$ & $\begin{array}{l}0.56(0.10- \\
3.22)\end{array}$ & 0.512 \\
\hline \multirow[t]{2}{*}{$\begin{array}{l}\text { Exposure to } \\
\text { smoking }\end{array}$} & Yes & $1(4)$ & $9(4)$ & $\begin{array}{l}0.94(0.11- \\
7.71)\end{array}$ & 0.952 \\
\hline & No & $25(96)$ & $211(96)$ & Ref & \\
\hline \multirow[t]{2}{*}{ Frequent AOM } & Yes & $9(35)$ & $16(7)$ & $\begin{array}{l}6.75(2.60- \\
17.54)\end{array}$ & $<0.001 *$ \\
\hline & No & $17(65)$ & $204(93)$ & Ref & \\
\hline \multirow[t]{2}{*}{ Allergy } & Yes & $17(65)$ & $81(37)$ & $\begin{array}{l}3.24(1.38- \\
7.61)\end{array}$ & $0.007 *$ \\
\hline & No & $9(35)$ & 139 (63) & Ref & \\
\hline Snoring & Yes & $16(62)$ & $38(17)$ & $\begin{array}{l}7.66(3.23- \\
17.18)\end{array}$ & $<0.001 *$ \\
\hline
\end{tabular}




\begin{tabular}{|llllll|} 
& No & $10(38)$ & $182(83)$ & Ref & \\
Delay speech & Yes & $9(35)$ & $28(13)$ & $\begin{array}{l}3.67(1.48- \\
8.93)\end{array}$ & 0.005* \\
& No & $17(65)$ & $192(87)$ & Ref & \\
\cline { 2 - 5 } & & & & \\
\hline
\end{tabular}

Considering the multivariate analysis, the prevalence in affected children was strongly associated with recurrent AOM ( $p=0.005$, OR: 5.14, 95\% Cl: 1.66-15.96), snoring ( $p=0.000$, OR: 6.32, 95\% Cl:2.32-17.26). Important to note all 26 children with OME had URTI, and reported snoring at night. This is possibly due to enlarged adenoids, which could affect the function of the Eustachian tube.

Sex, school attendance, exposure to smoking, allergy, and delayed speech were less associated with OME as shown in the table 3 below (Table 3 ):

Table 3: Shows multivariate analysis for the Factors associated with OME in children aged 2-12 years attending Paediatric Clinic at MNRH

\begin{tabular}{|llll|}
\hline Characteristics & odds ratio & $\mathbf{9 5 \%} \mathbf{~ C l}$ & P-value* $^{*}$ \\
\hline Male child & 2.22 & $0.80-6.20$ & 0.127 \\
\hline School attendance & 2.78 & $0.82-9.44$ & 0.102 \\
\hline Exposure to smoking & 0.22 & $0.01-3.23$ & 0.269 \\
\hline Frequent AOM & $\mathbf{5 . 1 4}$ & $\mathbf{1 . 6 6 - 1 5 . 9 6}$ & $\mathbf{0 . 0 0 5 *}$ \\
\hline Allergy & 1.49 & $0.56-3.99$ & 0.429 \\
\hline Snoring & $\mathbf{6 . 3 2}$ & $\mathbf{2 . 3 2}-\mathbf{1 7 . 2 6}$ & $\mathbf{0 . 0 0 0 *}$ \\
\hline Delayed speech & 1.99 & $0.64-6.20$ & 0.235 \\
\hline
\end{tabular}

*Statistically significant risk factors.

\section{Discussion}

This study set out to determine the prevalence and associated factors of otitis media with effusion among children aged 2-12 years attending Paediatric Clinic at Mulago National Referral Hospital.

\section{Prevalence of otitis media with effusion}

The prevalence of otitis media with effusion in this study was found to be $11 \%$. All 26 children with OME had bilateral OME, there were no children with unilateral OME. This is similar to the prevalence of OME (11.9\%) found in a study done by Els et al in South Africa, in 2016[10], where 109 children aged 2-12 years were recruited. 
Also, a study done by Caylan R et al, in Turkey, in 2006, found the prevalence of OME was $11.1 \%$ in children aged 5-12 years. This study had the similar findings to our study, even though they didn't have in their study children younger than 5 years[11].

In another cross-sectional study done by Chibuike et al, in Nigeria, in 2017[5] the prevalence of OME was reported to be $25.2 \%$ in children aged 1-6 years. In this study, the prevalence of OME was higher than what we found in our study. This could be attributed to the fact that it was a community study conducted in Sub region of Nigeria, which is characterized by high rainfall and humidity. It is also known as an industrial area with high air pollution. Another reason could be they considered tympanograms types $B$ and $\mathrm{C}$ as diagnosis of OME.

Aydemir $\mathrm{G}$ et al, in Turkey, in 2011[12], found $16 \%$ of 423 children 7-12 years enrolled had OME. This prevalence was higher as well compared to ours, the reason may be due to the fact that they considered the types $B$ and $C$ tympanograms as indicating of OME. In our study, the diagnosis of OME was based on type B tympanogram (flat curve).

Bisso $F$ (unpublished data), in Uganda, in 2002[6], found the prevalence of OME was $14.1 \%$ in school going children aged 4-6 years. This prevalence was slightly similar to our study, the only difference the former was a community study and didn't include children less than 4 years and older than 6 years.

\section{Factors associated with otitis media with effusion}

We found frequent episodes of URTI, recurrent otitis media with effusion, and snoring to be factors strongly associated with otitis media with effusion, this is similar to that reported by F.Martines et al [13] where snoring $(p<0.0001 ; O R=3.86,95 \% C l: 2.72-5.47)$, recurrent acute otitis media $(p<0.0015$; $\mathrm{OR}=2.54,95 \% \mathrm{Cl}: 1.41-4.61)$, frequent URTI ( $<<0.0001 ; \mathrm{OR}=3.17,95 \% \mathrm{Cl}: 2.22-4.52)$ were factors associated with otitis media with effusion.

Our results were also similar to the findings of Kiris $M$ et al [14] who found that snoring $(p<0.0001)$ and URTI ( $p<0.0001$ were important associated factors with otitis media with effusion. But they didn't consider recurrent acute otitis media as variable, which was included in our present study.

In a study done by Aydemir G.et al in 2011 [12], URTI ( $p<0.05)$, snoring $(p<0.05)$, frequent episodes of acute otitis media $(p<0.05)$ were reported to be predictors to otitis media with effusion, which are similar to the findings of our study.

Snoring reported in our 26 children with bilateral OME, could be due to a mechanical obstruction of the nasopharynx by enlarged adenoid, which could affect the function of the Eustachian tube.

\section{Limitation of the study}

Otitis media with effusion leads to conductive hearing loss in affected children, we would have wished to assess the degree, types and configuration of the hearing loss, using the diagnostic Auditory Brainstem 
Response machine, we were not able to do it.

\section{Conclusion}

The prevalence of OME in children aged 2-12 years attending Paediatric Clinic at MNRH was found to be $11 \%$, which is low or high to compare to other studies.

URTIs, recurrent acute otitis media, and snoring are found to be predictors to OME at Pediatric clinic at MNRH. We recommend to all Pediatricians and other medical professionals working at Pediatric unit to always give special attention to children presenting with URTI and other ENT conditions such as hearing loss, recurrent acute otitis media, snoring at night. Those who are not responding to the treatment should be referred early to ENT clinic for further management. Government should make policies on tympanometric test at Paediatric Clinic at Mulago National Referral Hospital, Kampala Uganda for early detection of hearing loss in children, which could indicate the presence of OME, thus to prevent them from sequelae that may arise.

\section{Abbreviations}

ABR

Auditory Brainstem Response

AOM

Acute Otitis Media

$\mathrm{CHL}$

Conductive Hearing Loss

CHS

College of Health Sciences

$\mathrm{dB}$

deci-Bel

$\mathrm{dBHL}$

decibel Hearing Level

ENT

Ear

Nose and Throat

EAC

External Auditory Canal

$\mathrm{HL}$

Hearing Loss

$\mathrm{MoH}$

Ministry of Health

MNRH

Mulago National Referral Hospital 
OME

Otitis Media with Effusion

PTA

Pure Tone Audiometry

SNHL

Sensorineural Hearing Loss

SOMREC

School Of Medicine Research and Ethics Committee

TM

Tympanic Membrane

URTI

Upper Respiratory Tract Infection.

\section{Declarations}

\section{Acknowledgements}

We would like to thank all our Lecturers in Ear, Nose and Throat Department, Makerere University, in a special way Dr Justine Namwagala, Dr Rym Hidour, Dr Tumweheire, Dr Bugembe, Dr Ricky Byaruhanga, Dr Kakande, Dr Ndoleriire, ..., all the Paediatricians in the Paediatric clinic at MNRH, Parents and children for their participation in this study. We wish also to thank Nurse Sarah, Audiologist Josephine, Audiologist Feston Bwambale, Paediatrician Emma Nsalazi Bambi who have been involved in collecting data for this study.

\section{Funding}

This work did not receive any funding.

\section{Availability of data and materials}

The datasets used and/or analyzed during the current study are not publicly available due to legal and ethical reasons but are available from the corresponding author on reasonable request.

\section{Ethics approval and consent to participate}

Ethical approval was obtained on the $01^{\text {st }}$ April 2019 from Makerere University College of Health Sciences, School of Medicine Research and Ethics Committee. All study methods were performed in accordance with the relevant guidelines and regulations of Declaration of Helsinki A written informed consent/assent was obtained from participants. The results of this study were kept strictly confidential, and used only for research purposes. The name was not appearing anywhere on the coded forms with the information. 


\section{Consent for publication - Not applicable}

\section{Competing interests}

The authors declared they have no competing interests.

\section{Authors' contributions.}

KB: conception and design of the study, data collection, data interpretation, drafting and review of the manuscript, JN: conception and design of the study data analysis, data interpretation, drafting and review of the manuscript, $\mathrm{RH}$ : conception and design of the study data analysis, data interpretation, drafting and review of the manuscript, ENS: contributed to the data collection, reviewed study data, and contributed to manuscript writing. All authors read and approved the final manuscript.

\section{References}

1. Rosenfeld RM, Shin JJ, Schwartz SR, Coggins R, Gagnon L, Hackell JM, et al. Clinical practice guideline: otitis media with effusion (update). Otolaryngology-Head and Neck Surgery. 2016;154(1_suppl):S1-S41.

2. Baggi E, Semino M, Bianchini S, Fattizzo M, Rosazza C, Esposito S, et al. Middle ear problems in children hospitalised because of lower respiratory tract infections: A comparison between two cohorts in Burundi and Italy. International journal of pediatric otorhinolaryngology. 2013;77(12):1984-6.

3. Parmar S, Davessar JL, Singh G, Arora N, Kansal L, Singh J. Prevalence of Otitis Media with Effusion in Children with Hearing Loss. Indian Journal of Otolaryngology and Head \& Neck Surgery.1-6.

4. Biagio L, Swanepoel DW, Laurent C, Lundberg T. Paediatric otitis media at a primary healthcare clinic in South Africa. SAMJ: South African Medical Journal. 2014;104(6):431-5.

5. Chibuike N, d Lilly-Tariah O, Lucky O. Prevalence of Otitis Media with Effusion among Preschool Children in Port Harcourt, Nigeria. Glob J Oto. 2017;4(4):555644.

6. Bisso F. The prevalence of otitis media with effusion among 4-6 year old nursery school children in Kawempe devision, Kampala district. 2002.

7. Paradise JL, Rockette HE, Colborn DK, Bernard BS, Smith CG, Kurs-Lasky M, et al. Otitis media in 2253 Pittsburgh-area infants: prevalence and risk factors during the first two years of life. Pediatrics. 1997;99(3):318-33.

8. Rosenfeld RM. Evidence based otitis media: PMPH-USA; 2003.

9. Rosenfeld RM, Culpepper L, Doyle KJ, Grundfast KM, Hoberman A, Kenna MA, et al. Clinical practice guideline: otitis media with effusion. Otolaryngology-Head and Neck Surgery. 2004;130(5):S95-S118.

10. Els T, Olwoch I. The prevalence and impact of otitis media with effusion in children admitted for adeno-tonsillectomy at Dr George Mukhari Academic Hospital, Pretoria, South Africa. International journal of pediatric otorhinolaryngology. 2018;110:76. 
11. Caylan R, Bektas D, Atalay C, Korkmaz O. Prevalence and risk factors of otitis media with effusion in Trabzon, a city in northeastern Turkey, with an emphasis on the recommendation of OME screening. European Archives of Oto-Rhino-Laryngology and Head \& Neck. 2006;263(5):404-8.

12. Aydemir G, Ozkurt F. Otitis media with effusion in primary schools in Princes' Islands, Istanbul: prevalence and risk factors. Journal of International Medical Research. 2011;39(3):866-72.

13. Martines F, Bentivegna D, Maira E, Sciacca V, Martines E. Risk factors for otitis media with effusion: case-control study in Sicilian schoolchildren. International journal of pediatric otorhinolaryngology. 2011;75(6):754-9.

14. Kırıs M, Muderris T, Kara T, Bercin S, Cankaya H, Sevil E. Prevalence and risk factors of otitis media with effusion in school children in Eastern Anatolia. International journal of pediatric otorhinolaryngology. 2012;76(7):1030-5.

\section{Figures}

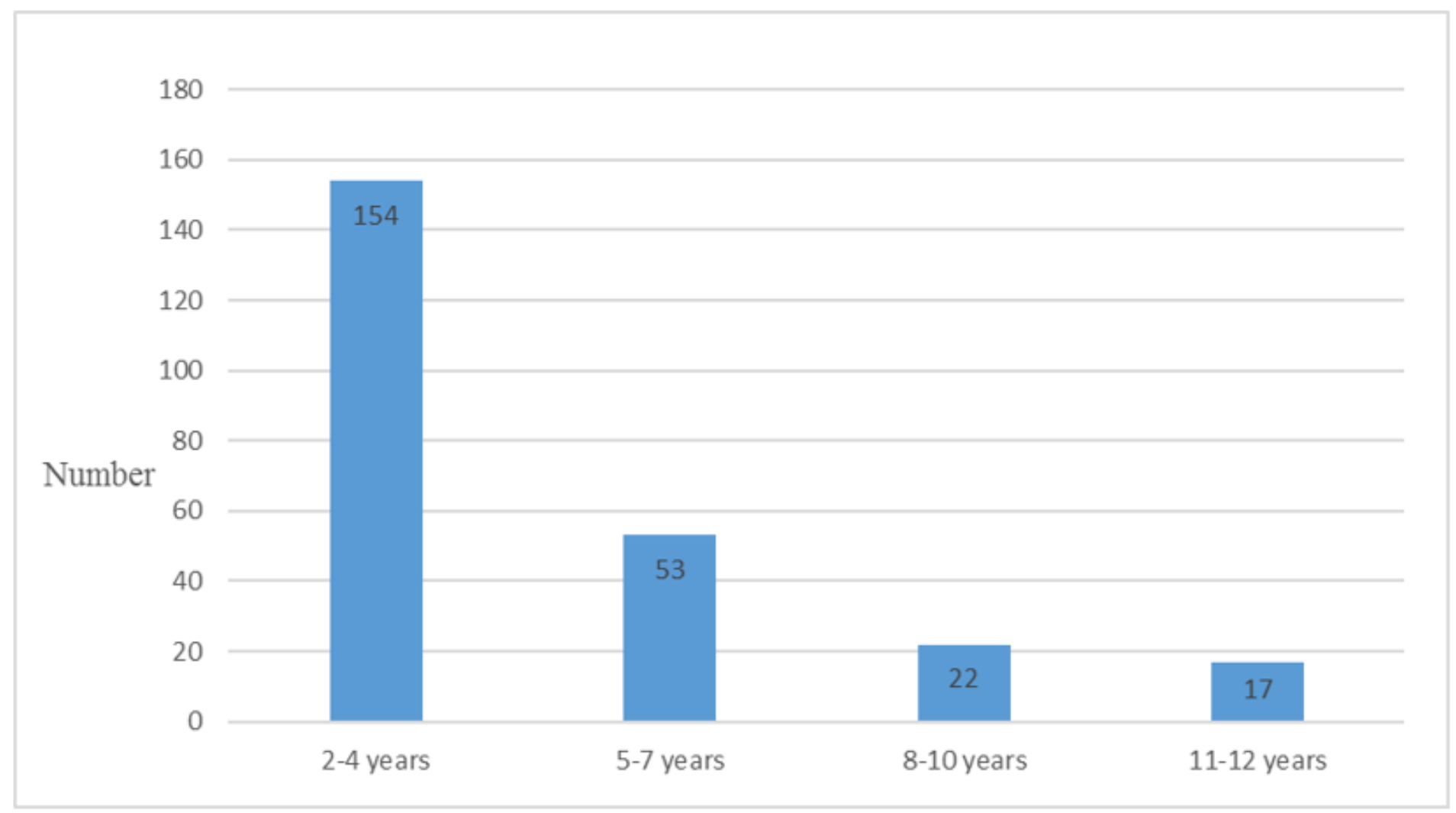

Figure 1

Shows the age distribution of the study participants 


\section{THE PREVALENCE OF OME IN CHILDREN AGED 2-12 YEARS}

ATTENDING PAEDIATRIC CLINIC

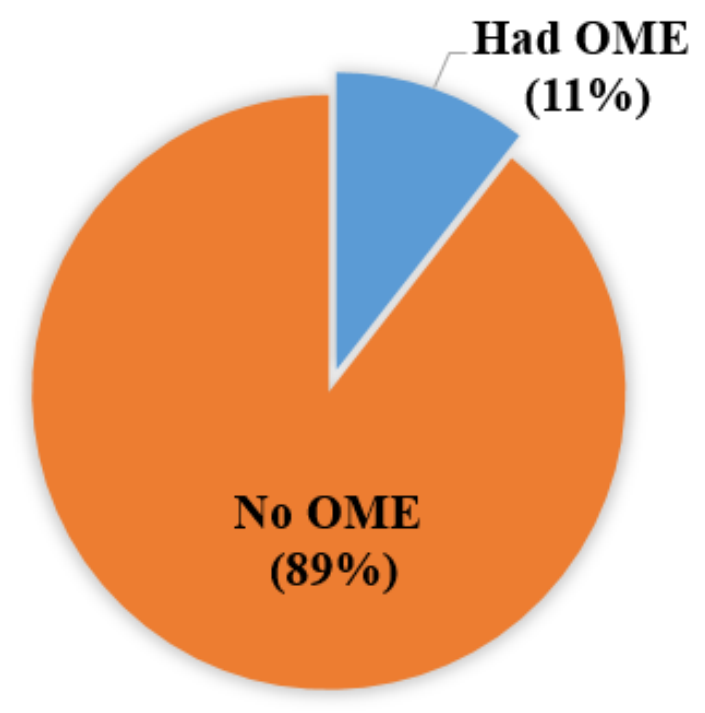

Figure 2

Pie-chart showing the prevalence of OME in children aged 2-12 years attending Paediatric Clinic 